\title{
Pleistocene extinction and geographic singularity explain differences in global felid ensemble structure
}

\author{
Miriam Mariana Morales ${ }^{1,2}$ (D) . Norberto Pedro Giannini ${ }^{3,4,5}$
}

Received: 29 April 2020 / Accepted: 13 January 2021

(c) The Author(s), under exclusive licence to Springer Nature Switzerland AG part of Springer Nature 2021

\begin{abstract}
Extant felids are hyper-carnivorous predators that originated in Asia c. 11 Mya and diversified in 8 distinct lineages, with 41 species surviving to the Recent. These species occupy almost every terrestrial habitat available in the four continental land masses they occupy and exhibit morphological and behavioral specializations to various locomotor styles and hunting modes. Today, distinct felid ensembles inhabit each continent and major biogeographic region. How the differential structuring of these ensembles was generated, and which evolutionary processes shaped these differences across ensembles, are key emerging questions. Using multivariate statistics, we analyzed a large dataset of 31 cranial and 92 postcranial linear variables describing shape and functional proxies of the entire skeleton of extant felids. We statistically demonstrate the existence of nine felid morphotypes at the global scale, whose occurrence is characteristic of different continental or biogeographic ensembles. Phylogenetically explicit analyses show that morphotypes from different felid lineages converged in different continents, but still ensembles remain distinct due to the fact that various morphotypes are missing in several of those ensembles. However, fossil evidence suggests that most of these missing morphotypes were represented by species from those territories that went extinct during the Quaternary. Furthermore, reconstructing the hypothetical felid ensembles before Pleistocene extinctions rendered the continental felid faunas remarkably more similar to each other than they presently are, leaving their remaining, relatively minor differences to outstanding geographic singularities of each continental land mass.
\end{abstract}

Keywords Complete skeleton $\cdot$ Felidae $\cdot$ Ecomorphology $\cdot$ Macroevolution

Miriam Mariana Morales

moralesmiriamm@gmail.com

1 Instituto de Ecorregiones Andinas (INECOA), Consejo Nacional de Investigaciones Científicas y Técnicas (CONICET), Universidad Nacional de Jujuy (UNJu), Jujuy, Argentina

2 Centro de Estudios Territoriales Ambientales y Sociales, Facultad de Ciencias Agrarias, Universidad Nacional de Jujuy, Alberdi 47, C.P. 4600 San Salvador de Jujuy, Jujuy, Argentina

3 CONICET-Fundación Miguel Lillo, Unidad Ejecutora Lillo, San Miguel de Tucumán, Argentina

4 Facultad de Ciencias Naturales e Instituto Miguel Lillo, Universidad Nacional de Tucumán, Miguel Lillo 205, C.P. 4000 San Miguel de Tucumán, Tucumán, Argentina

5 Department of Mammalogy, American Museum of Natural History, New York, USA 


\section{Introduction}

An ensemble is a phylogenetically bound group of species that use a similar set of resources within a community (Fauth et al 1996). How ensembles of different organisms have formed along macro-evolutionary time expanses and across geography remains elusive (Stokstad 2009). Felids represent a recently radiated, widely distributed group of predators that may be used as example to explore the drivers structuring ensembles and how they change over time and space. Living cat species belong to subfamily Felinae that originated in Asia c. 11 Mya, during the late Miocene (Johnson et al 2006). Felinae diversified into 8 distinct lineages (Johnson et al 2006) and ancestral species of this successful carnivoran clade soon spread to all major landmasses they inhabit today-Eurasia, Africa and the Americas. With 41 species surviving to the Recent (Kitchener et al 2017), the group is arranged into characteristically distinct ensembles in each major landmass and biogeographic region (Johnson et al 2006; Table 1). At present, these various felid ensembles vary widely across continents, both in composition and ecomorphology. For example, the Neotropical region is richest in felid species (11 species); the Neartic region virtually has no Panthera species (jaguars, Panthera onca Linnaeus 1758, are only marginally present in New Mexico) and no felids smaller than lynxes; only in Africa and the Middle East the fast-running cheetah (Acynonix jubatus Schreber 1775) is present. Continental ensembles differ also in more subtle morpho-functional structuring for reasons yet unknown. Remarkably, Pleistocene ensembles were richer, and they appear considerably different from those of today (e.g. Turner and Antón 1997), but how they differ and why, are still open questions.

Morphologically, extant felids are considered to be quite homogeneous, although some general differences have been recognized in skull shape and postcrania (e.g., Christiansen 2007, 2008; Lewis and Lague 2010; Sicuro and Oliveira 2010). Analysis of complete-skeleton datasets for Neotropical and African ensembles of felids identified general form differences among felid species which could be associated to locomotor modes (Morales and Giannini 2013a, b). This kind of integral analysis based on individuals with complete skeleton has not been performed for the whole subfamily, or indeed for any group of mammals, as it is extremely difficult to find museum specimens with both complete skull and most of their skeletal elements even for charismatic species like felids. This is an even larger problem for most fossil felid species that are known to have inhabited different continents; their phylogenetic relationship have been studied based on fragmentary material, and these studies provide descriptions of their general (known and estimated) anatomy but also reveal many instances of distributions that are at odds with present-day ensembles (e.g., lion-like forms in North America and cheetah-like species in North America, Europe and Asia; e.g., Barnett et al 2005 and 2006; Christiansen and Mazák 2008; Montellano-Ballesteros and Carbot-Chanona 2009).

In this work, we analyzed ensembles of felids across the Globe from an ecomorphological and macro-evolutionary perspective. Based on previous work (Morales and Giannini 2010, 2013a, b), we hypothesized that phylogeny and body size played a major role in the evolution of those ensembles. Using a comprehensive morphological approach based on carefully selected specimens with complete skull and postcrania, we propose that perceived differences between present-day morpho-functional ensembles are explained to some extent by singularities of continents and largely, by selective Pleistocene extinction. 
Table 1 Conformation of studied ensembles

\begin{tabular}{|c|c|c|c|c|c|c|c|c|c|}
\hline \multirow[b]{2}{*}{$\mathrm{Sp}$} & \multicolumn{2}{|c|}{ AMERICA } & \multicolumn{5}{|c|}{ AFRICA } & \multicolumn{2}{|c|}{ ASIA } \\
\hline & $\mathrm{N}$ & $\mathrm{NE}$ & $\mathrm{AF}$ & AF-T & $\mathrm{AF}+\mathrm{SOAS}$ & $\mathrm{NAF}+\mathrm{SOAS}$ & EUAS & PAL & OR \\
\hline Aju & & & $\mathrm{X}$ & $\mathrm{X}$ & $\mathrm{X}$ & $\mathrm{X}$ & $\mathrm{X}$ & & \\
\hline $\mathrm{Cau}$ & & & $\mathrm{X}$ & $\mathrm{X}$ & $X$ & & & & \\
\hline Cca & & & $\mathrm{X}$ & $X$ & $X$ & $X$ & $X$ & & \\
\hline $\mathrm{Cba}$ & & & & & & & $\mathrm{X}$ & & $\mathrm{X}$ \\
\hline Ctk & & & & & & & $\mathrm{X}$ & & $\mathrm{X}$ \\
\hline Fbt & & & & & & & $\mathrm{X}$ & $X$ & \\
\hline Fca & & & & & & & & & \\
\hline Fch & & & & & $X$ & $X$ & $X$ & & $X$ \\
\hline Oma & & & & & & & $X$ & $X$ & \\
\hline Fmt & & & $\mathrm{X}$ & & $X$ & $\mathrm{X}$ & $\mathrm{X}$ & & \\
\hline Fng & & & $\mathrm{X}$ & $\mathrm{X}$ & $\mathrm{X}$ & & & & \\
\hline Fly & & & $\mathrm{X}$ & $\mathrm{X}$ & $\mathrm{X}$ & $\mathrm{X}$ & $\mathrm{X}$ & $\mathrm{X}$ & $\mathrm{X}$ \\
\hline Fsi & & & & & & & $X$ & $\mathrm{X}$ & \\
\hline Hya & $\mathrm{X}$ & & & & & & & & \\
\hline Lco & $\mathrm{x}$ & & & & & & & & \\
\hline Lge & $\mathrm{X}$ & & & & & & & & \\
\hline Lgt & $\mathrm{X}$ & & & & & & & & \\
\hline Lgu & $\mathrm{X}$ & & & & & & & & \\
\hline $\mathrm{Lja}$ & $\mathrm{X}$ & & & & & & & & \\
\hline Lpa & $\mathrm{x}$ & & & & & & & & \\
\hline $\mathrm{Lti}$ & $\mathrm{X}$ & & & & & & & & \\
\hline Lwi & $\mathrm{X}$ & & & & & & & & \\
\hline Lse & & & $\mathrm{X}$ & $\mathrm{X}$ & $\mathrm{X}$ & & & & \\
\hline Lca & & $\mathrm{X}$ & & & & & & & \\
\hline Lly & & & & & & & $\mathrm{X}$ & $\mathrm{X}$ & \\
\hline Liu & & & & & & & $\mathrm{X}$ & $\mathrm{X}$ & \\
\hline Lru & & $\mathrm{X}$ & & & & & & & \\
\hline Pmm & & & & & & & $\mathrm{X}$ & & $\mathrm{X}$ \\
\hline $\mathrm{Pbg}$ & & & & & & & $\mathrm{X}$ & & $\mathrm{X}$ \\
\hline Pjv & & & & & & & $\mathrm{X}$ & & $\mathrm{X}$ \\
\hline Ppl & & & & & & & $\mathrm{X}$ & & $\mathrm{X}$ \\
\hline Pru & & & & & & & $\mathrm{X}$ & & $\mathrm{X}$ \\
\hline Pvi & & & & & & & $\mathrm{X}$ & & $\mathrm{X}$ \\
\hline Pco & $\mathrm{X}$ & $X$ & & & & & & & \\
\hline Ple & & & $\mathrm{X}$ & $\mathrm{X}$ & $\mathrm{X}$ & & $\mathrm{X}$ & & $\mathrm{X}$ \\
\hline Pon & $\mathrm{X}$ & & & & & & & & \\
\hline Ppd & & & $\mathrm{X}$ & $\mathrm{X}$ & $\mathrm{X}$ & $\mathrm{X}$ & $\mathrm{X}$ & & $\mathrm{X}$ \\
\hline Pti & & & & & & & $\mathrm{X}$ & & $\mathrm{X}$ \\
\hline Pun & & & & & & & $\mathrm{X}$ & $\mathrm{X}$ & \\
\hline Nne & & & & & & & $\mathrm{X}$ & & $\mathrm{X}$ \\
\hline Ndi & & & & & & & $\mathrm{X}$ & & $\mathrm{X}$ \\
\hline
\end{tabular}

In the first line is the region in which each ensemble is included

$A F$ Africa, $T-A F$ Tropical Africa, EUAS Eurasia, $N$ Neotropical (proxi for South America), NAF North Africa, NE Neartic (proxi for North America), OR Oriental, PAL Paleartic, SWAS South West Asia (=Middle East) 


\section{Materials and methods}

\section{Material studied}

We measured linear morphometric data (see below) from 461 specimens representing all 41 currently recognized extant felid species (as in Kitchener et al. 2017) stored in the following collections: Argentina: Centro Nacional Patagónico, Puerto Madryn (CNP), Colección de mamíferos del Centro de Ecología Aplicada, Junín de los Andes (Dirección de Parques Nacionales; APN- provisional acronym), Colección de Mamíferos del Instituto Argentino de Investigaciones de las Zonas Áridas, Mendoza (CMI); Colección del Grupo de Ecología Comportamental de Mamíferos, Bahía Blanca (CGECM); Colección Mamíferos Lillo, Tucumán (CML), Private Collection Marcelo Carrera, Puerto Madryn (MC); Museo Argentino de Ciencias Naturales "Bernardino Rivadavia", Buenos Aires (MACN), Museo de Ciencias Naturales de la Universidad Nacional de Salta, Salta, Argentina (MCN-UNSa), Museo de La Plata, La Plata (MLP); Museo Municipal de Ciencias Naturales "Lorenzo Scaglia", Mar del Plata, Argentina (MMPMa); Bolivia: Colección Boliviana de Fauna, La Paz (CBF), Museo Noel Kempf, Santa Cruz de la Sierra (MNK); Peru: Museo de Historia Natural, Universidad Nacional Mayor de San Marcos, Lima (MUSM); United States: Academy of Natural Science of Drexel University, Philadelphia (ANSP), American Museum of Natural History, New York (AMNH), Field Museum of Natural History, Chicago (FMNH), National Museum of Natural History, Washington D.C. (USNM); Uruguay: Colección Zoología de Vertebrados, Facultad de Ciencias, Universidad de la República, Montevideo (ZVC-M), Museo Nacional de Historia Natural, Montevideo (MNHN). The greatest difficulty to sample felid specimens across these different institutions was the limited availability of complete skeletons of adult specimens. A complete adult dentition primarily defined the adult stage of the specimens, but whenever possible, we selected specimens with fully fused epiphysis of the long bones. Wild, sexed specimens were selected with priority. Specimens used are listed in Supplementary Appendix I.

\section{Morphometric variables}

We defined a set of 31 cranial and 92 postcranial variables with a descriptive and functional significance (Figs. S1-S4), e.g. the length of the olecranon is equivalent to the loading arm of the m. triceps brachii for arm extension (O in Supplementary Fig. S3) and the condyle-basal length is often used as a proxy for body size of specimens (CBL in Supplementary Fig. S1). These sets were developed in previous studies (Morales and Giannini 2010, 2013a, b) and included key dimensions of the skull, selected vertebrae, girdles, limb long bones, autopods, and the tail (Morales 2012; Morales and Giannini 2010, 2013a, b). All variables are illustrated in Supplementary Figures S1-S4; a detailed description of variables is extracted from Morales and Giannini (2013b) and given in Supplementary Appendix II. Postcranial morphofunctional variables differ from Morales and Giannini (2013a, b) only in lacking one measurement related to the brachialis muscle and having in addition the length of tail. The latter is defined as the percentage of tail length (PT) with respect to the head plus body length, when this information was available for the specimen, or as the median from published data (chiefly Sunquist and Sunquist 2002, but adding other specific literature). To our knowledge this represents the most comprehensive dataset compiled to 
date for extant felids. All measurements were taken using digital calipers to the nearest $0.1 \mathrm{~mm}$.

\section{Data analysis}

We applied the multivariate ordination method, principal component analysis (PCA), for three different data sets, called "skull" with $N=451$ and including all 41 species; "postcranium" with $N=67$ and including 35 species from all genera; and "combined" dataset with $N=61$, including 34 species, also from all genera (see Morales and Giannini 2010, 2013a, b). These analyses (all based on variance-covariance matrices) were used to determine the ecomorphological structuring of skull and skeletal variation, separately and altogether; in this context, ordination plots resulting from each PCA are taken as representations of the ecomorphological space of all species of Felinae. In order to increase the number of specimens and species under analysis, we performed an additional PCA called "combined and reduced" dataset $(N=84 ; 35$ species $)$ with a reduced number of variables, following Morales and Giannini (2013b; variables used for this analysis are marked with an asterisk in Supplementary Figs. S1-S4 and Appendix II) and adding tail length as described above.

All PCA were done also correcting for the influence of raw body size by using Mosimann variables and the geometric mean (see Morales 2012; Morales and Giannini 2010, 2013a). The geometric mean (GM) is a size variable derived from the $N$ th root of the product of $N$ measurements (here, all the variables measured in a specimen, transformed to base-10 logarithm). Using this value, each measurement is replaced by a Mosimann shape variable, i.e., the ratio of a particular measurement to the overall GM (Meachen-Samuels and Van Valkenburgh 2009a, b).

We quantified phylogenetic influence on the ecomorphological structuring using canonical phylogenetic ordination (CPO; Giannini 2003). This phylogenetic comparative method estimates historical effects on comparative data using the monophyletic groups of a cladogram (specifically, partitions of an unrooted network, which equivalent to clades of rooted trees; partition = node numbers in Fig. 1). CPO was originally defined as a multivariate PGLS, with the phylogeny incorporated as an explanatory variable set in a general linear model; this is in contrast with most PGLS, in which the phylogeny is coded in the error term (see Giannini 2003). CPO provides both, the statistical demonstration of phylogenetic signal and the specific-clade composition of that signal, because the explanatory variable set is composed of binary variables each representing one tree partition or clade. Thus, $\mathrm{CPO}$ via simulations is able to indicate which clades are significant (sequentially testing inclusion of clades in a final multivariate linear model) and the total variation explained by the selected tree partitions. Therefore, we choose CPO because it provides a complete rendering of the phylogenetic effect on the morphological data: both the size effect (total variance explained by the phylogeny) and the specific clades of that effect, all tested within a Monte Carlo simulation framework. We used the tree from Johnson et al. (2006) modified as shown in Fig. 1 following chiefly Kitchener et al. (2017) to include all species of extant felids. The tree modification consisted in pruning those species no longer recognized by the last taxonomic revision of the Family (Kitchener et al. 2017) and placing the new species considered valid in nodes according to their expected relationship (as in Kitchener et al. 2017). That is, these species were located as sisters of those species of which they were separated; for example, the terminal Neofelis nebulosa in Johnson et al. (2006) was split in the two sister species, Neofelis nebulosa and Neofelis diardi (following Buckley-Beason et al. 2006); or changing a relationship if suggested by new evidence, e.g. Felis catus was 
Fig. 1 Phylogenetic relationships among 41 extant species of felids reporting significant partitions (arrows; Canonical Phylogenetic Ordination) for each analysis of skull, postcranium and combined datasets (see Supplementary Tables S3-S14 for more details). Phylogenetic relationships modified from Johnson et al. (2006) by adding newly recognized species following Kitchener et al. (2017). Dashed lines in the cladogram represent changes from the tree of Johnson et al. (2006). Species colors: blue, Paleartic; red, AF+SWAS; green, Neotropics; violet, Oriental; light blue, Neartic; black, more than one region. Vertical dashed lines, estimated dates for trans-continental migrations; Red dots, trans-continental migrations suggested by Johnson et al. (2006). UN-, untransformed data; SC, size corrected data. *Species with no postcranial data available; + , species with no combined data available. Numbers in clades represent partitions used for CPO analyses. Arrows represent retained partitions after stepwise selection $(P$ value $<0.01)$. a 8.5-8.0 my migration from Eurasia to North America; b 6.7-6.2 my migration from North America to Asia; c 2.7 my, migration from North America to South America; d 2.7 my migration from Asia to Africa and Americas (data from Johnson et al. 2006)

changed as sister of Felis lybica instead of Felis silvestris after Driscol et al. (2007) and Geigl and Grange (2018). Tree partitions were tested individually using 4999 Monte Carlo unrestricted permutations run with the program Canoco 4.02 (ter Braak 1995); significant tree partitions (alpha set to 0.01) were included in a forward stepwise model.

We used biogeographic regions suggested by Kreft and Jetz (2010) to construct ensembles by the simple presence of species in each region. We considered 6 regions as biogeographic ensembles: Neartic, Neotropical, Oriental, Paleartic, Tropical Africa and North Africa + South West Asia, but we also analyzed whole continents (see Table 1). Based on published data (e.g. Sunquist and Sunquist 2002, 2009; see Supplementary Table S1), we mapped known ecological features onto the PCA ordination diagram (combined and complete dataset). For prey size preference we followed Meachen-Samuels and Van Valkenburgh (2009b) and recognized three categories: (1) small prey consumers, felines that eat predominantly prey smaller than their own body size; (2) large prey consumers, felines that eat predominantly prey larger than their own body size; and (3) mixed-prey consumers, felines that consume both small and large prey indistinctly or according to availability. For habitat preference we classified three general groups: steppe, savanna, and forest. Lastly, for locomotion type we also followed Meachen-Samuels and Van Valkenburgh (2009b) considering the frequency of climbing: (1) terrestrial, including those species that rarely climb trees; (2) scansorial, species that climb frequently but rarely hunt on trees; and (3) arboreal, species that spend most of their time, and frequently hunt, on trees.

We defined morphotypes by grouping species that were close in morphospace in resulting ordination diagrams of combined dataset analyses, both reduced and complete (Fig. 2B and Supplementary Fig. S10). Using the untransformed "combined-and-reduced" dataset ( $N=84 ; 35$ species), we applied a one-way analysis of similarity (ANOSIM) as implemented in PAST v. 3.12 (Hammer et al. 2001). This multivariate, non-parametric analysis is based on a ranked dissimilarity matrix and lacks normal and similarity-of-variance assumptions (Clarke 1993); ANOSIM was used to test whether the identified morphotypes were significantly distinct from each other in morphospace. This test was applied globally, and in pairwise morphotype comparisons using 9999 permutations. Additionally, we performed D-PGLS, which is a phylogenetic analysis of variance based on a generalization of phylogenetic general least squares (PGLS; Adams 2014). This analysis is appropriate for evaluating trends in high-dimensional biological multivariate data with a phylogenetic component. We applied D-PGLS using the mean axis coordinate (across specimens) for each species in all 28 PCA axes obtained from the PCA based on the same dataset. With D-PGLS we evaluated whether ecomorphs were significantly different among each other while accounting for phylogenetic relatedness. We used the tree modified from Johnson et al (2006; as in Fig. 1) and Grafen's (1989) method to estimate branch lengths on the 


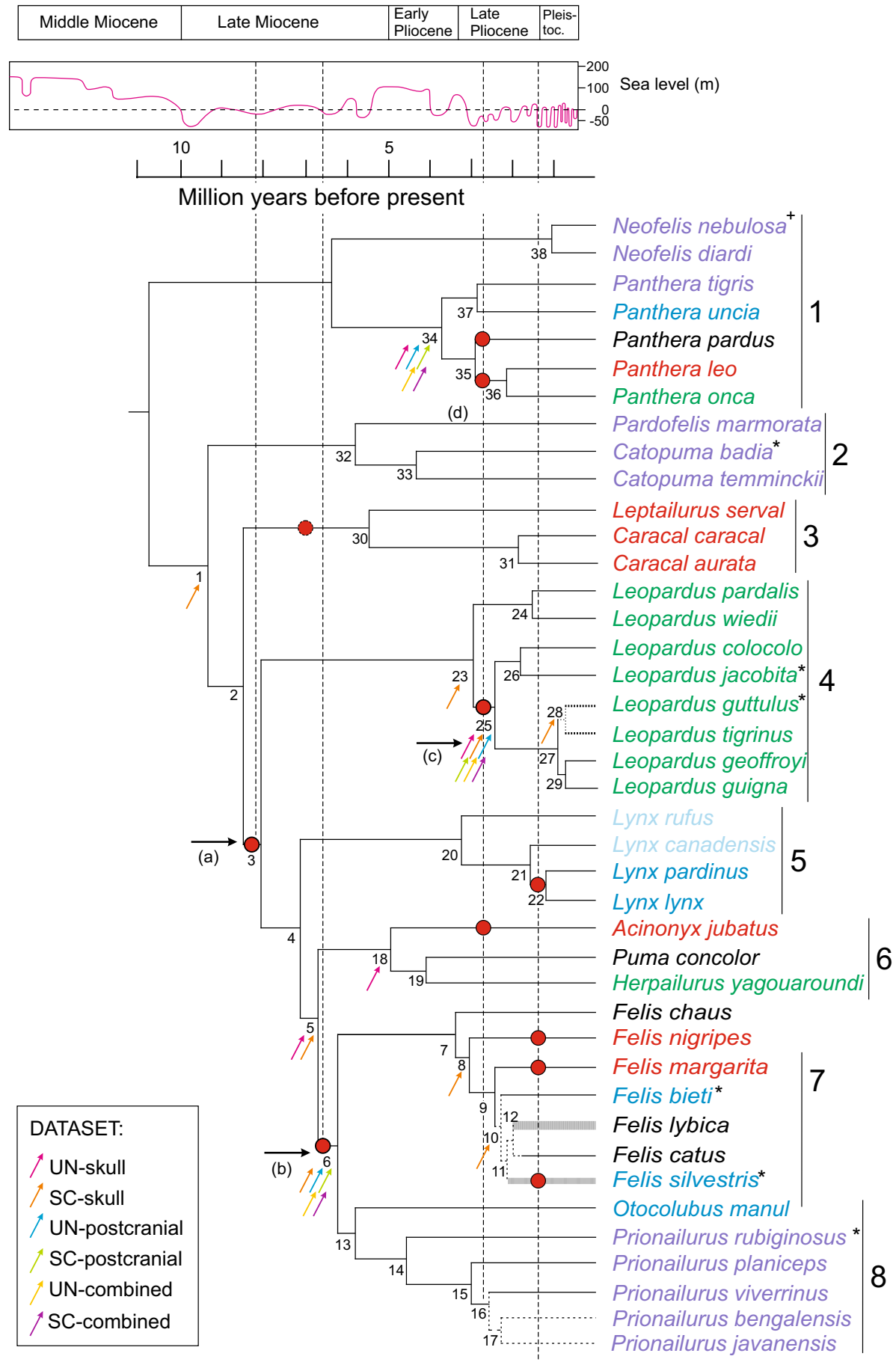



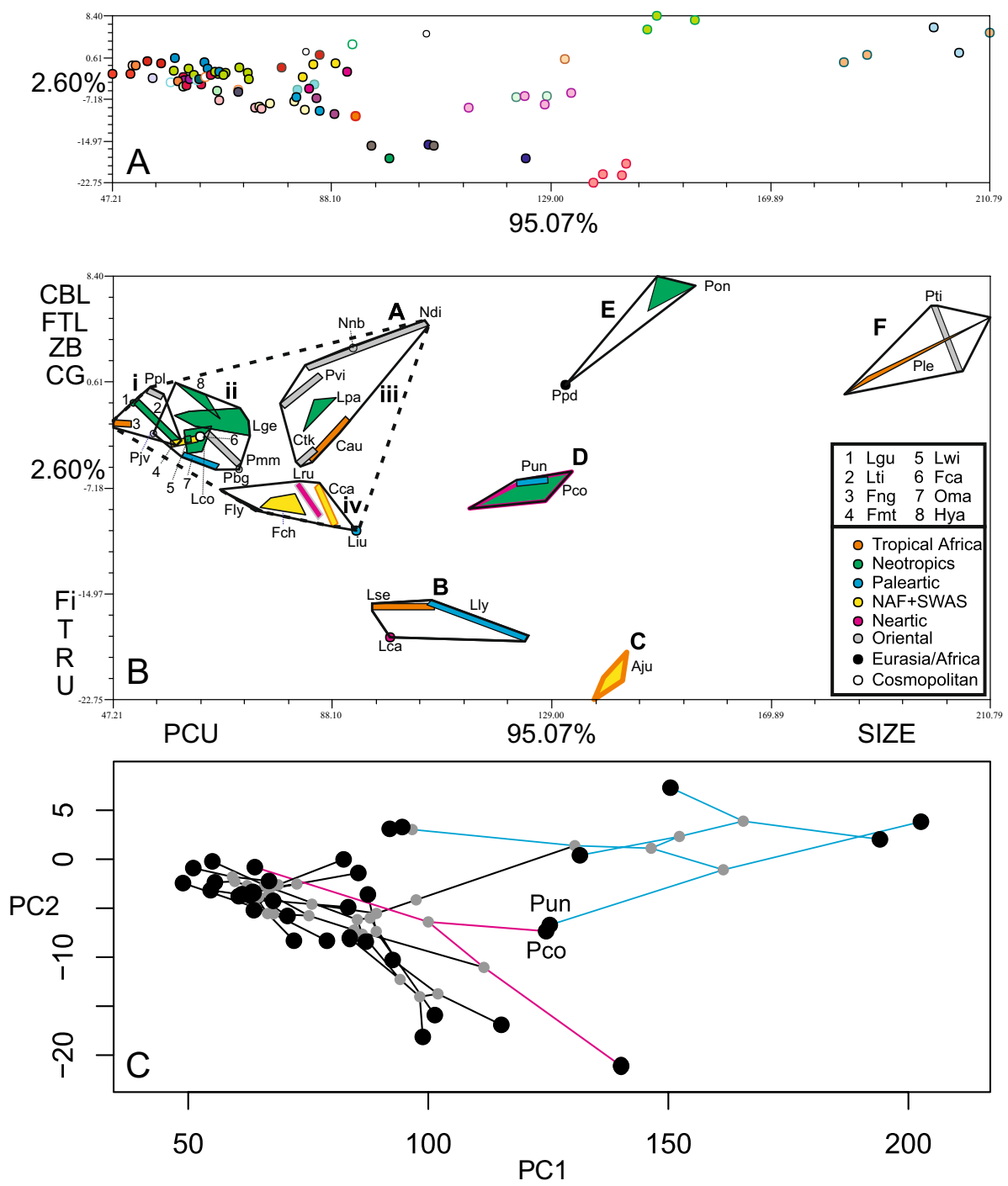

Fig. 2 a, b PCA plot of subfamily Felinae. Combined and reduced dataset $(8$ cranial +19 postcranial variables; $N=84 ; 35$ species). a Specimen scores scaled proportionally to the variation of each axis ( $\lambda^{0.5}$ for the ith PC axis, with $\lambda$ representing the ith eigenvalue). Colors represent each species as seen in $\mathrm{B}$. $\mathbf{b}$ Normalized ordination diagram (specimen scores scaled to unit eigenvector). Colors indicate the biogeographic region where the species are present. Polygons represent morphotypes: (A) generalized felids: (1) very small species; (2) small species; (3) midsized forest-dwelling species; (iv) jumping species; (B) second group of jumping species; (C) sprinting species; (D) rupicolous, or rock-dwelling species; (E) mid-to-large scansorial species; (F) large, predominantly terrestrial species. Aju, Acinonyx jubatus*, Cau, Caracal aurata, Cca, Caracal caracal, Ctk, Catopuma temminkii, Fca, Felis catus, Fch, Felis chaus, Fmt, Felis margarita, Fng, Felis nigripes, Fly, Felis lybica, Hya, Herpailurus yagouaroundi, Lca, Lynx canadensis, Lco, Leopardus colocolo, Lge, Leopardus geoffroyi, Lgu, Leopardus guigna*, Liu, Lynx pardinus*, Lly, Lynx lynx*, Lpa, Leopardus pardalis, Lru, Lynx rufus, Lse, Leptailurus serval, Lti, Leopardus tigrinus, Lwi, Leopardus wiedii*, Ndi, Neofelis diardi, Nnb, Neofelis nebulosa*, Oma, Otocolubus manul, $\mathrm{Pbg}$, Prionailurus bengalensis, Pco, Puma concolor*, Ple, Panthera leo, Pmm, Pardofelis marmorata, Pon, Panthera onca, Ppd, Pantera pardus*, Ppl, Prionailurus planiceps, Pti, Panthera tigris*, Pun, Panthera uncia, Pvi, Prionailurus viverrinus. C. Phylomorphospace of extant felids obtained using PC1 and PC2 coordinates of combined reduced dataset using convevol package in R (Stayton 2015). Colors highlight the lion lineage (blue) and the puma lineage (pink). Grey dots represent internal nodes 
phylogeny. We run the analysis with R package geomorph v. 3.3.1 (Adams et al 2020), conducting 999 permutations to assess statistical significance.

We searched for evidence of ecomorphological convergence (considered as a patternbased concept) among species clustered in the same morphotype using the approach proposed by Stayton (2015). This distance-based technique calculates phenotypic similarity among putatively convergent species (statistic C1 in Stayton 2015) tested with respect to their ancestor; we applied this technique both to distance calculated over the original-variable data matrix, and to the matrix of PCA coordinates (all PCA axes, or rotated matrix), and used the tree modified from Johnson et al (2006) as in Fig. 1. For each species, we calculated the mean of measurements (or axis coordinate) across specimens and this value was introduced in the analysis. The observed $\mathrm{C} 1$ statistic was compared to a null expectation generated by 999 simulations of evolution under a Brownian Motion model (Stayton 2015). For convergence analysis we used convevol package in R (Stayton 2018; R Core Team 2020).

Finally, we reconstructed extant ensemble configuration by color coding the statistically significant morphotypes present in each ensemble (Fig. 3). On this layout, we reconstructed hypothetical Pleistocene Felinae ensembles by assigning fossil species to the morphotypes they putatively belong in, based on approximate size category, anatomical traits, and phylogenetic relationships (see references in Table 2) and adding them to the extant ensembles' configurations. We added Pleistocene fossil species separately in each major biogeographic
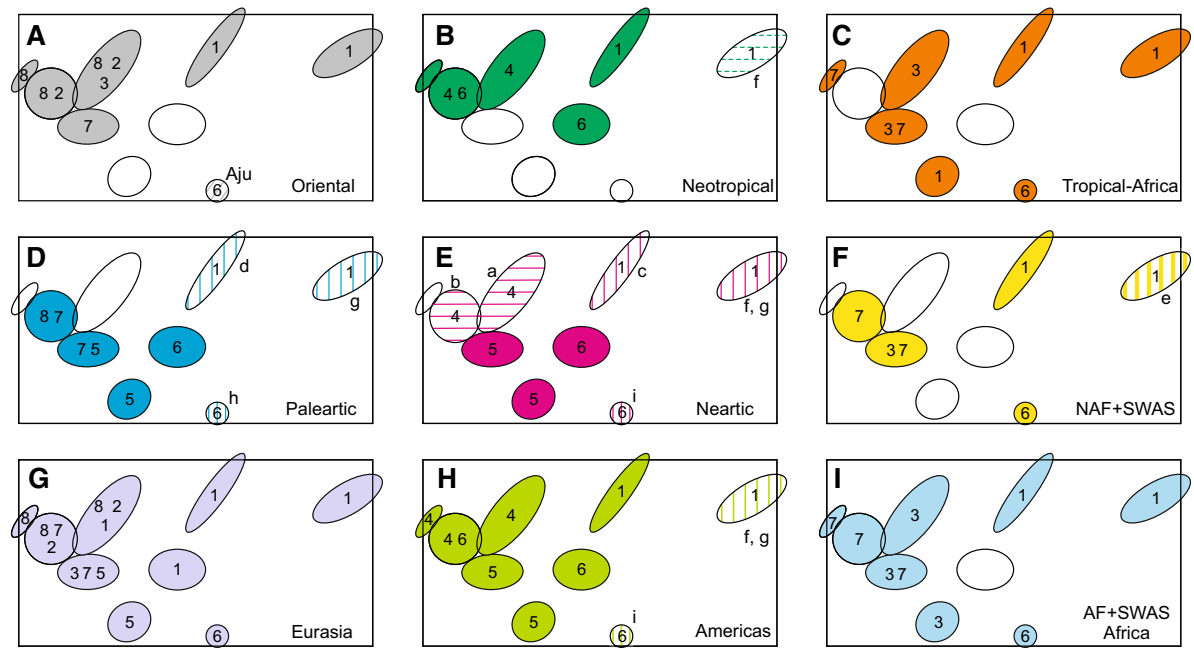

Fig. 3 Comparative morphotype composition of biogeographically defined felid ensembles, current (solid color) and hypothetical (dashed color) after adding Pleistocene species lost to extinction in different ensembles. Oblique dashing indicates that species representing the lost morphotype went extinct in historical times (the cheetah in the oriental region). Vertical dashing indicates morphotypes documented in the fossil record before Pleistocene extinctions in any given ensemble. Horizontal dashing indicates that species representing the morphotype were present in a restricted area of the geographical region before Pleistocene extinctions. Dotted-stripped morphotypes indicate that the presence of the morphotype is negligible in the ensemble (see Table 2). Numbers represent felid lineages present in each ensemble: (1) Lion; (2) Bay Cat; (3) Caracal; (4) Ocelot; (5) Lynx; (6) Puma; (7) Domestic Cat; (8) Bengal Cat. Low case letters represent fossil species as represented in Table 2 


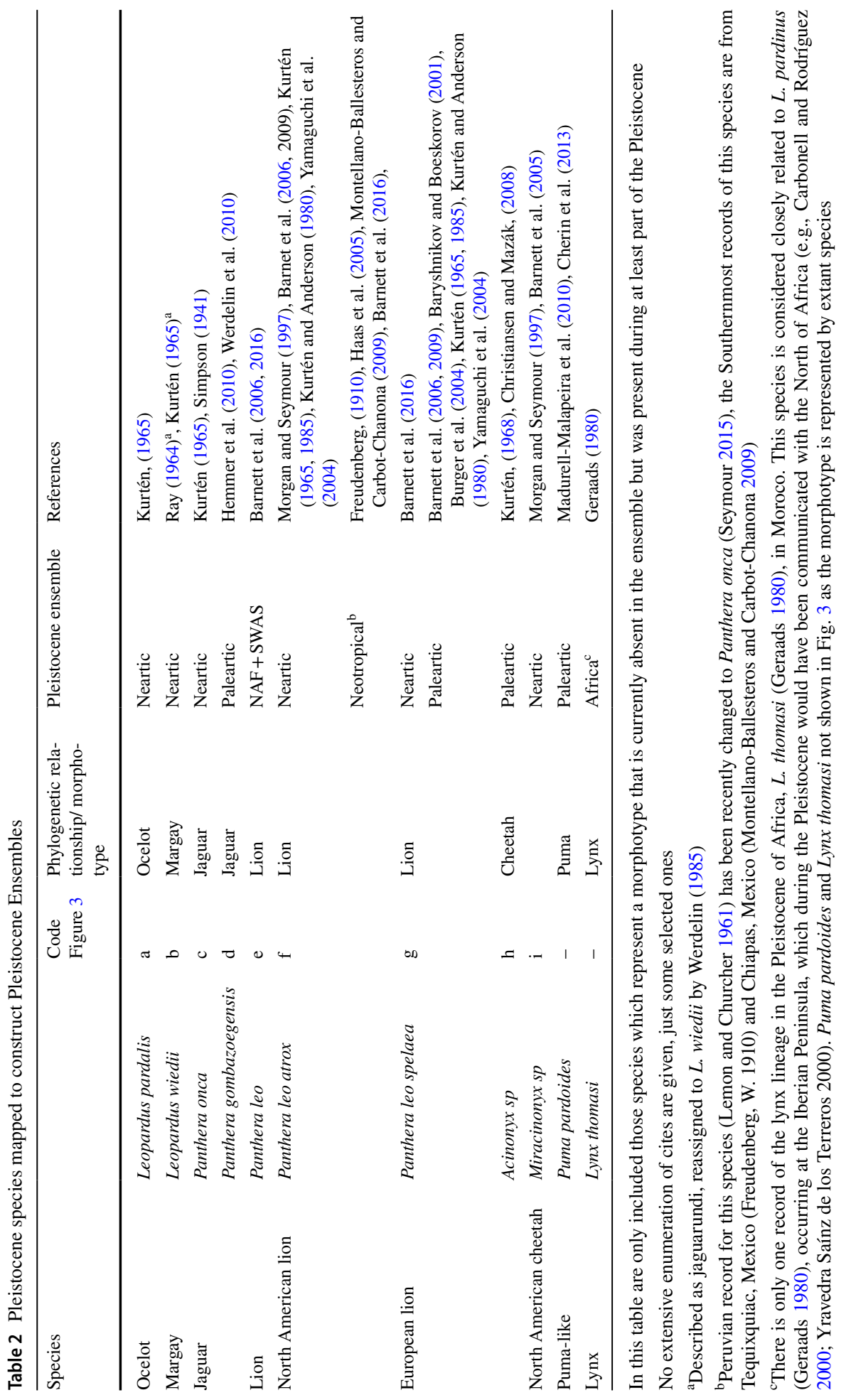


region and continental mass, thereby completing the putative morphotype set per region otherwise lost to extinction (Fig. 3; Table 2).

\section{Results}

Each PCA, based on skull, postcranial, and combined datasets (reduced and complete), revealed particular aspects of ecomorphology of the global felid ensembles (see below and Fig. 2a, b, Table 3 and Supplementary Figs. S5-S15 and Table S2). However, postcranial data generally dominated the perceived morphofunctional patterns when combined with skull data (see Supplementary Figs. S5 versus S8 and S10), so the morphospace of the combined analyses were similar to those of the postcranial set. The analysis of the subset of 27 complete skeleton variables presented very similar results to those of the complete dataset of all skeleton (123 variables; see Fig. 2b versus Supplementary Fig. S10). Given this, we centered the discussion on the first set with more specimens and less (thereby redundant) variables (see detailed results in Supplementary Figs. S5-S15 and Table S2).

Complete-skeleton analyses (with the reduced number of morphometric variables) first revealed five contiguous groups defined along the PC1 (Fig. 2a, b and Supplementary Fig. S10). As predicted, these groups represented size, but more precisely concomitant sizerelated (likely static allometric) variation. An inverse relationship between leg length and skull size was apparent along the PC2: felids in the negative side of PC2 were long-legged, small-headed jumping or sprinting species (PC2 in Fig. 2b and Supplementary Fig. S10; see also Table 3 and Supplementary Table S2).

Patterns observed after mapping known ecological characteristics (locomotion, prey size and habitat) onto this morphospace are shown in Supplementary Figs. S11-S13. Overall, the felid morphospace $(\mathrm{PC} 1+\mathrm{PC} 2)$ showed a pattern of species clustered by their common morphology and overall size, which translated into functional similarities. We statistically confirmed the presence of group structuring both using ANOSIM (Mean rank within $=455.4$; Mean rank between $=2015 ; R=0.8945 ; P \leq 0.001)$ and D-PGLS ( $F=47.365$ and $P=0.001$ ). We identified six major morphotypes in the felid morphospace, and some subtypes, thus totaling nine morphotypes (Fig. 2b and Supplementary Fig. S10). Our pairwise comparisons confirmed the significance of all nine groupings (9999 permutations each, all $P \leq 0.001$; sequential Bonferroni; Table 4). These significant groups included: (A) generalized felids, composed by all small and most median species (see below); within this main group, four subgroups could also be distinguished: (1) very small species, all terrestrial and small-prey hunters; (2) small species, small-prey hunters with various locomotor modes but no specific adaptations for climbing; (3) mid-sized forestdwelling species, including felids with various locomotor modes and capable to hunt both small and large prey; and (4) small-to-mid-sized jumping species, mostly short-tailed species (all but F. lybica Foster, 1780) with extraordinary jumping capabilities. (B) specialized jumping species, with short tail and extraordinary jumping capabilities, but morphologically more derived than other jumping species (5); (C) sprinting species, including the single true sprinter, the cheetah; (D) rupicolous species, placing together Panthera uncia Schreber 1775 and Puma concolor Linnaeus 1771, thereby supporting Gonyea's (1976) proposal of pumas being primarily adapted to montane environments, in spite of the wide range of habitats occupied by this species; (E) mid-to-large scansorial species, which also hunt large prey; and finally, $(\mathrm{F})$ large species, terrestrial large-prey hunters. 
Table 3 Results of principal component analyses for reduced combined dataset with ( $R$-Comb-ZC) and without size correction $(R$-Comb; $N=84 ; 35$ species): loadings of each variable on the first two axes extracted and the corresponding eigenvalues, percent of total variation per axis, and cumulative percentage of successive axes (\%ac.)

\begin{tabular}{|c|c|c|c|c|}
\hline \multirow[t]{2}{*}{ Variables } & \multicolumn{2}{|l|}{$R$-Comb } & \multicolumn{2}{|l|}{$R$-Com-ZC } \\
\hline & I & II & I & II \\
\hline \multicolumn{5}{|c|}{ Cranial variables } \\
\hline ATL & 22.4867 & 5.8916 & 0.0079 & 0.0072 \\
\hline CBL & 53.5791 & 14.1670 & -0.0184 & 0.0014 \\
\hline CG & 38.2471 & 9.1970 & -0.0024 & 0.0038 \\
\hline FTL & 28.9117 & 9.2767 & -0.0137 & 0.0061 \\
\hline IOW & 13.5939 & 1.6882 & 0.0260 & 0.0080 \\
\hline $\mathrm{MeD}$ & 14.1058 & 5.0140 & 0.0357 & 0.0262 \\
\hline $\mathrm{PC}$ & 9.1216 & -1.5442 & -0.0230 & -0.0211 \\
\hline ZB & 42.8260 & 9.2579 & -0.0096 & -0.0025 \\
\hline \multicolumn{5}{|c|}{ Postcranial variables } \\
\hline A & 23.1522 & 2.6559 & 0.0020 & -0.0084 \\
\hline $\mathrm{F}$ & 69.2477 & -4.0465 & -0.0166 & -0.0168 \\
\hline $\mathrm{Fi}$ & 53.0286 & -12.1355 & -0.0239 & -0.0250 \\
\hline GL & 17.3612 & -1.8452 & 0.0402 & 0.0071 \\
\hline GM & 16.3426 & -0.7766 & 0.0431 & 0.0048 \\
\hline $\mathrm{H}$ & 59.9442 & -2.0544 & -0.0170 & -0.0166 \\
\hline HD & 16.7434 & 3.4619 & 0.0314 & 0.0132 \\
\hline IQ & 22.0292 & 0.6621 & 0.0236 & 0.0037 \\
\hline LDT & 30.4505 & 1.3954 & -0.0004 & -0.0060 \\
\hline LI & 30.3134 & 2.5081 & 0.0023 & -0.0016 \\
\hline MC & 26.0971 & 3.6836 & 0.0108 & 0.0044 \\
\hline $\mathrm{P}$ & 60.1684 & 4.4641 & -0.0038 & -0.0023 \\
\hline PQR & 31.8648 & 3.3486 & 0.0097 & -0.0089 \\
\hline PR & 41.2584 & -1.0842 & -0.0010 & -0.0048 \\
\hline PT & -0.4540 & 4.7697 & -0.1106 & 0.0456 \\
\hline $\mathrm{R}$ & 51.3015 & -10.3512 & -0.0137 & -0.0278 \\
\hline $\mathrm{T}$ & 54.7688 & -11.6908 & -0.0246 & -0.0250 \\
\hline $\mathrm{U}$ & 66.2882 & -8.3203 & -0.0154 & -0.0239 \\
\hline WP & 12.6876 & 1.5069 & -0.0065 & 0.0099 \\
\hline WPI & 31.8455 & 4.1040 & 0.0085 & 0.0053 \\
\hline \multicolumn{5}{|c|}{ Eigen values } \\
\hline$\Lambda$ & $41,112.8271$ & 1122.5276 & 0.0229 & 0.0072 \\
\hline$\%$ & 95.0666 & 2.5957 & 51.4100 & 16.0516 \\
\hline$\%$ ac & 95.0666 & 97.6623 & 51.4100 & 67.4616 \\
\hline
\end{tabular}

For acronyms of variables see Supplementary Figs. S1-S4 and Appendix I

Canonical Phylogenetic Ordination indicated that common ancestry, as predicted, significantly explained from $30.9 \%$ and up to $71.4 \%$ of the morphological variation in skull, postcranium, and the two sets combined, with and without size-correction (Fig. 1; Supplementary Tables S3-S14). The tree partition that segregated the largest 
Table 4 Results of Pairwise comparisons of ANOSIM analysis performed on untransformed combined reduced dataset $(N=84 ; 35$ species $)$

\begin{tabular}{llllllllll}
\hline & Aii & $D$ & Aiii & $C$ & Aiv & $B$ & Ai & $F$ & $E$ \\
\hline Aii & & $0.0001^{*}$ & $0.0001^{*}$ & $0.0002^{*}$ & $0.0001^{*}$ & $0.0001^{*}$ & $0.0001^{*}$ & $0.0002^{*}$ & $0.0001^{*}$ \\
$D$ & 1 & & $0.0002^{*}$ & $0.0039^{*}$ & $0.0002^{*}$ & $0.0055^{*}$ & $0.0004^{*}$ & $0.0021^{*}$ & $0.0043^{*}$ \\
Aiii & 0.9468 & 0.9873 & & $0.0006^{*}$ & $0.0001^{*}$ & $0.0004^{*}$ & $0.0001^{*}$ & $0.0002^{*}$ & $0.0003^{*}$ \\
$C$ & 1 & 0.9603 & 1 & & $0.0006^{*}$ & $0.0155^{*}$ & $0.0031^{*}$ & $0.0078^{*}$ & $0.0314^{*}$ \\
Aiv & 0.7957 & 0.999 & 0.3324 & 1 & & $0.0003^{*}$ & $0.0001^{*}$ & $0.0001^{*}$ & $0.0004^{*}$ \\
$B$ & 0.9998 & 0.7547 & 0.8583 & 0.95 & 0.8588 & & $0.0015^{*}$ & $0.0076^{*}$ & $0.0086^{*}$ \\
Ai & 0.633 & 1 & 0.9847 & 1 & 0.9568 & 1 & & $0.0013^{*}$ & $0.0029^{*}$ \\
$F$ & 1 & 1 & 1 & 1 & 1 & 1 & 1 & & $0.0089^{*}$ \\
$E$ & 1 & 0.7738 & 0.9983 & 0.9479 & 1 & 0.9688 & 1 & 1 & \\
\hline
\end{tabular}

Above, $p$ values after sequencial Bonferroni; below, $R$ values for pairwise ANOSIM

*Statistically significant

pantherines [tiger, P. tigris Linnaeus 1758; lion, P. leo (Linnaeus1758); leopard, P. pardus (Linnaeus1758); jaguar, and snow leopard, P. uncia (Schreber 1775), partition 34 in Fig. 1] from all other felids was the most important one in all comparative analyses, but the one performed with skull dataset controlled by size (Supplementary Tables S4, S6, S8, S10, S12, S14). Postcranial and combined datasets, both untransformed and corrected by size, selected for the model the same partitions (see Fig. 1), i.e., partition 34 mentioned above, partition 25 (the group inclusive of most small Leopardus of the Americas, but L. wiedii Schinz 1821 and L. pardalis Linnaeus 1758) and partition 6 (the split of the domestic cat and the Bengal's cat lineages from the resto of the felids). Skull datasets incorporated more partitions to the model (especially the size corrected dataset). In the case of the skull dataset corrected by size, the most important group retained was 25 (a subgroup within Leopardus) and did not retain 34 in any step of the model (Table S6).

Our analyses allowed recognition of some morphotypes as the evolutionary product of lineage convergence, with evidence for more phenotypic similarity among species from different lineages than expected by chance. Those morphotypes were very small felids (Ai), small felids (Aii), mid-sized forest dwelling species (Aiii), small-to-midsized jumping species (Aiv), rupicolous species (D) and large species (F), in both the original-variables matrix and rotated (PCA-axes) matrix analyses (Table 5). This was also evident in the trajectory of descendant species in phylomorphospace (Fig. 2c). The most striking example of phylogenetic trajectory convergence is that of rupicolous Puma concolor from the Americas, and the snow leopard, Panthera uncia, from the Himalayas and up North to the Gobi and the Southern Siberian mountains (highlighted in Fig. 2c).

Reconstructed Pleistocene ensembles are shown in Fig. 3. Eurasia, Africa and the Americas, all exhibited the nearly complete set of nine morphotypes when Pleistocene fossils were relocated to the morphotype they putatively belong in (but see Africa below). Likewise, major biogeographic regions also recover a wider morphotype set after adding to the corresponding morphotypes those forms lost to Pleistocene extinctions, particularly the Neartic (5 morphotypes added) and the Paleartic (3 morphotypes added). 
Table 5 Convergence test quantification as suggested by Stayton (2015) applied with complete and reduced dataset

\begin{tabular}{lllll}
\hline Morphotype & $C 1$-measurments & $P$ value & $C 1$-coordinates & $P$ value \\
\hline Ai & 0.67698982 & $\mathbf{0 . 0 0 0}$ & 0.67698577 & $\mathbf{0 . 0 0 0}$ \\
Aii & 0.61377711 & $\mathbf{0 . 0 0 0}$ & 0.61377754 & $\mathbf{0 . 0 0 0}$ \\
Aiii & 0.68423091 & $\mathbf{0 . 0 0 0}$ & 0.68423207 & $\mathbf{0 . 0 0 0}$ \\
Aiv & 0.53384161 & $\mathbf{0 . 0 0 2}$ & 0.53384387 & $\mathbf{0 . 0 0 5}$ \\
B & 0.35332774 & 0.142 & 0.35332833 & 0.134 \\
C & NA & NA & NA & NA \\
D & 0.86351723 & $\mathbf{0 . 0 0 0}$ & 0.86351576 & $\mathbf{0 . 0 0 1}$ \\
E & 0.3519928 & 0.121 & 0.3519930 & 0.111 \\
F & 0.7788214 & $\mathbf{0 . 0 0 8}$ & 0.7788212 & $\mathbf{0 . 0 1 0}$ \\
\hline
\end{tabular}

Morphotypes are those observed in Fig. 2. $C 1$ calculates phenotypic similarity among putatively convergent species. $C 1$ measurements include the results obtained using the morphometric matrix directly, with average values of measurements for species with more than one individual. $C 1$ coordinates include results obtained using the coordinates of species of a principal component analysis, with average values of axis coordinate for species with more than one individual. Values in bold indicate statistically significant results

\section{Discussion}

\section{Extant ensembles}

The observed morphospace of extant felids obtained using skull and postcranial information altogether shows how size-related (likely mostly allometric) variation is a key factor. Size variation can be linked to different ecological aspects of felid species: groups specifically related to $\mathrm{PC} 1$ associated with a pattern of substrate use, such as arboreal and scansorial forms successively nested within the wider space of terrestrial forms, thereby restricting arboreality to small-to-mid-size felids (Supplementary Fig. S11). Size was also important when mapping preferred prey size, with PC1 showing a clear contrast between felids that mostly hunt and consume large prey, versus the remaining species, which specialize in hunting small or mix-sized prey (Supplementary Fig. S12). Size would not have such a strong effect on preferred habitats (Supplementary Fig. S13).

The evolutionary drivers for the existence of these groupings are unclear, but it seems likely that interspecific allometric change across species from different felid lineages gave rise to the main morphotypes recognized in this work. Felids are known for their considerable phenotypic plasticity when species co-exist in sympatry (Dayan et al 1990; Dayan and Simberloff 2005; Tellaeche et al 2018). At a local scale, character displacement has been proposed among species and even between sexes of co-existing species (Kiltie 1984; Dayan et al 1990). This may apply at a wider geographic scale, for instance within continental ensembles (as could be interpreted when analyzing speciation in the caracal lineage; see Johnson et al 2006). However, at a global scale, observed groupings are not expected as a result of direct competition or sympatric niche partitioning, given that only subsets of species co-occur in one given continent or biogeographic region. Thus, forces driving or affecting the structuring of ensembles at that scale must be different. Remarkably, our results revealed that each global felid morphotype has representatives in several biogeographic regions, with no morphotype being exclusive of any region—not even the sprinting 
morphotype, represented solely by the cheetah (Figs. 1, 3). It has been shown that reconstructed dispersal of ancestral species along the evolution of felid lineages has led to the settlement of different ensembles across biogeographic regions (Johnson et al 2006). The pattern we recovered thus reflects either lineage-level convergence of morphotypes across biogeographic regions (statistically demonstrated in six out of nine of the morphotypes recognized in this work), or common origin followed by active dispersal across major biogeographic barriers such as intercontinental ocean expanses. This strongly suggests that part of the involved species are evolutionarily heterogeneous (diverse origin) but ecomorphological equivalents (convergent) across biogeographic regions (Ricklefs 1998; Biggins et al 2011).

The unfolding of the present-day ensemble structure, and the macroevolutionary processes that shaped their differences, are therefore questions emerging from these patterns. Our comparative analyses revealed that phylogeny was one key factor: in our sample, results showed how phylogeny explains significant (and sometimes large) amounts of observed ecomorphological space structuring (see above). Remarkably, two of those significant partitions (see Fig. 1), retained in five or all of the six phylogenetic comparative analyses, coincide with previously proposed intercontinental migrations through Beringia (partition 6 at 6.7-6.2 my) and the Isthmus of Panama (partition 25 at $2.7 \mathrm{my}$ ). Also, the segregation of big felids (i.e. lion, tiger, jaguar, snow leopard and leopard) from the rest of the felids was recovered as an important partition with all datasets but transformed skull morphology only (Fig. 1). Other of these partitions defined lineages; partition 18, the puma lineage and partition 23, the ocelot lineage. That is, our analyses identified the key nodes that significantly explained the observed morphological structure, some of which were in turn associated with previously identified major biogeographic processes of intercontinental dispersal (see Johnson et al. 2006).

\section{Pleistocene ensembles}

The fossil record suggests that extinctions affected felids along their dispersal process, and after they settled in different continents (e.g., Turner and Antón 1997; Werdelin et al. 2010). Prevalent extinction of the large-terrestrial felid morphotype (Fig. 3) could suggest a connection with megafaunal extinctions (Koch and Barnosky 2006). We argue that Pleistocene extinctions of varying severity, worst in the Neartic due to extensive glaciation along most of the territory, blurred the ample felid ensemble similarity across all major global regions due to a combination of (1) pre-Pleistocene evolutionary convergence, and (2) biogeographic dispersal (e.g. Johnson et al. 2006). It is remarkable that the extinct sabretoothed subfamily Machairodontinae (not covered in this study) was also represented in all the same landmasses as extant Felinae, as well as in most current biogeographic regions (e.g., Turner and Antón 1997; Werdelin et al 2010), thus potentially evolving in parallel the same fate of extant groups.

Interestingly, not all biogeographic regions attained the full set of nine discovered morphotypes after accounting for documented Pleistocene extinctions. Most remarkable pattern was that of the rupicolous morphotype, absent in only one major land mass, Africa, where extensive mountain ranges are lacking, and isolated mountains are smaller and disconnected as compared with other continents (UNEP 2002; Price et al 2013). Also notable is the absence of the jumping, sprinting, and large felids morphotypes in South America, unexpected given the expanses of tropical savannah and other environments used by species of these morphotypes in other continents. In this case, the Panamanian land bridge 
must have worked as a strong biogeographic filter (Behling et al 2010; Carrillo et al 2015; Bacon et al 2016), preventing these felid morphotypes (as well as many other different mammals, such as bovids) from colonizing South America. Altogether these patterns suggest two general, underlying factors for a given morphotype to be absent in a given biogeographic region: (1) failure of the species (or its ancestors) to overcome a biogeographic barrier or filter; and (2) lack of suitable habitat in the colonization target area.

\section{Conclusion}

Ecomorphological evolution of felids led to the appearance of nine, statistically recognizable morphotypes which originated repeatedly from the eight major phylogenetic lineages of Felinae. Three morphotypes, sprinting, mid-large scansorial, and large terrestrial (Fig. 2b and Supplementary Fig. 10) evolved from the same two lineages (puma lineage and lion lineage; 1 and 6 in Fig. 3) and were present in all land masses, thus requiring intercontinental dispersal for the given morphotype to be established in one given landmass. Morphotypes involving very small, small, mid-sized forest dwelling species, small-to-mid-sized jumping species, rupicolous species (puma and snow leopard) and very large pantherines (tiger and lion) evolved convergently in each land mass from various local lineages. These lineage-dependent processes of dispersal and/or convergence combined, inferred from phylogenetic comparative results, and interpreted in the light of biogeographic processes, led, in our reconstructions of Pleistocene ensembles, to the occurrence of all morphotypes in each major landmass, except when geographic singularities (e.g., lack of extensive mountain ranges, or suitable landbridge for dispersal) prevented arrival, establishment, or evolution of a given morphotype. Pleistocene extinctions further shaped the disparity of continental ensembles we see today by selective extinctions of varying severity. Hypothetical re-composition of extinct lineages in the four major landmasses inhabited by felids (the Americas, Africa, and Eurasia; Fig. 3), and in most large-scale biogeographic regions, rendered a remarkably homogeneous pattern of Pleistocene ensembles across the Globe. This led us to propose that Pleistocene extinctions and geographic singularities, imposed differences in otherwise remarkably uniform global felid ensembles originally shaped by processes of dispersal and convergence.

Supplementary Information The online version contains supplementary material available at https://doi. org/10.1007/s10682-021-10103-2.

Acknowledgments We want to acknowledge all curators and personal involved in all collections visited (institutions in alphabetical order): Nancy Simmons, Eileen Westwig, Eleanor Hoeger, Brian O'Toole (AMNH); Ned Gilmore (ANSP); Ulyses Pardiñas (CNP); James Aparicio, Julieta Tordoya (CBF); Martín Monteverde (APN); Ricardo Ojeda (CMI); Mauro Lucherini, Estela Luengos Vidal (CGECM); Rubén Barquez, Mónica Díaz (CML); Marcelo Carrera (MC); Daniel Hernández (ZVC-M); Lawrence Heaney, William Stanley (FMNH); David Flores, Valentina Segura, Pablo Teta, Sergio Lucero (MACN); Pablo Perovic, Jorge Samaniego (MCN-UNSa); Víctor Pacheco, Carlos Tello (MUSM); Diego Verzi, Itatí Olivares, Cecilia Morgan (MLP); Damián Romero, Alejandro Dondas, Fernando Scaglia (MMPMa); Enrique González, Yennifer Hernández, José González (MNHN); Norka Rocha (MNK); Don Wilson, Darrin Lunde, Kristofer Helgen, John Ososky; Alfred Gardner, Linda Gordon, Jeremy Jacobs (USNM). Thanks to Per Ericson, Olavi Grönwall and Francisco Prevosti for facilitating photographic records of specimens of the Swedish Museum of Natural History, Stockholm and National Museum of Nature and Science, Tokyo respectively. MMM acknowledge Virginia Abdala and Sergio Vizcaíno for their support along her thesis. We thank Lars Werdelin for improving an earlier version of the manuscript and Jessica Fratani for her help in statistical analysis. Thanks to the reviewers and editor for their extremely constructive suggestions. This work was partially supported by CONICET, a Short-Term Visitor Fellowship granted by Smithsonian Institution and a 
Roosevelt Memorial Award granted by the American Museum of Natural History to MMM. We thank PICT 2015-0708 to MMM and PICT 2015-2389 and PICT 2016-3682 to NPG.

Author contributions MMM and NPG conceived the ideas and designed methodology and contributed to the shaping and production of the manuscript. MMM measured all specimens, carried out the statistical analysis and prepared figures, tables and Supplementary Information. All authors contributed critically to the drafts and gave final approval for publication.

Funding This work was partially supported by Consejo Nacional de Investigaciones Científicas y Técnicas, a Short-Term Visitor Fellowship granted by Smithsonian Institution and a Roosevelt Memorial Award granted by the American Museum of Natural History to MMM. We thank Agencia Nacional de Promoción de la Investigación, el Desarrollo Tecnológico y la Innovación, Fondo para la Investigación Científica y Tecnológica (PICT 2015-0708; PICT 2015-2389 and PICT 2016-3682).

Data availability and material Data deposited in the Mendeley repository: https://doi.org/10.17632/fntx8 pt8fv.1. Specimens used are stored in the Institutions declared in Material and Methods section.

\section{Compliance with ethical standards}

Confict of interest The authors declare that they have no conflict of interest.

Consent to participate Consent to participate and for publication.

\section{References}

Adams DC (2014) A method for assessing phylogenetic least squares models for shape and other highdimensional multivariate data. Evolution 68:2675-2688

Adams D, Collyer M, Kaliontzopoulou A (2020) Geomorph: Software for geometric morphometric analyses. R package version 3.3.1. Available from https://cran.r-project.org/package=geomorph (accessed November 2020)

Bacon CD, Molnar P, Antonelli A et al (2016) Quaternary glaciation and the Great American Biotic Interchange. Geology 44:375-378

Barnett R, Barnes I, Phillips MJ et al (2005) Evolution of the extinct sabertooths and the American cheetahlike cat. Curr Biol 15:589-590

Barnett R, Yamaguchi N, Barnes I et al (2006) The origin, current diversity, and future conservation of the modern lion (Panthera leo). Proc R Soc B 273:2159-2168

Barnett R, Shapiro B, Barnes I et al (2009) Phylogeography of lions (Panthera leo ssp.) reveals three distinct taxa and a late Pleistocene reduction in genetic diversity. Molec Ecol 18:1668-1677

Barnett R, Zepeda Mendoza ML, Rodrigues Soares AE et al (2016) Mitogenomics of the extinct cave lion, Panthera spelaea (Goldfuss, 1810), resolve its position within the Panthera cats. Open Quatern 2:p4

Baryshnikov G, Boeskorov G (2001) The Pleistocene cave lion Panthera spelaea (Carnivora, Felidae) from Yakutia, Russia. Cranium 18:7-24

Behling H, Bush M, Hooghiemstra H (2010) Biotic development of quaternary amazonia: a palynological perspective. In: Hoorn C, Wesselingh FP (eds) Amazonia: landscape and species evolution: a look into the past. Wiley-Blackwell Publishing Ltd., Chichester, pp 335-345

Biggins DE, Hanebury LR, Miller BJ et al (2011) Black-footed ferrets and Siberian polecats as ecological surrogates and ecological equivalents. J Mammal 92:710-720

Buckley-Beason VA, Johnson WE, Nash WG et al (2006) Molecular evidence for species-level distinctions in clouded leopards. Curr Biol 16:2371-2376

Burger J, Rosendahl W, Loreille O et al (2004) Molecular phylogeny of the extinct cave lion Panthera leo spelaea. Mol Phylogenetics Evol 30:841-849

Carbonell E, Rodríguez XP (2000) El Pleistoceno inferior de la Península Ibérica. SPAL Rev Prehist Arqueol Univ Sevilla 9:31-47

Carrillo JD, Forasiepi A, Jaramillo C et al (2015) Neotropical mammal diversity and the Great American Biotic Interchange: spatial and temporal variation in South America's fossil record. Front Genet 5:451 
Cherin M, Iurino DA, Sardella R (2013) Earliest occurrence of Puma pardoides (Owen, 1846) (Carnivora, Felidae) at the Plio/Pleistocene transition in western Europe: New evidence from the Middle Villafranchian assemblage of Montopoli, Italy. CR Palevol 12:165-171

Christiansen P (2007) Comparative bite forces and canine bending strength in feline and sabertooth felids: implications for predatory ecology. Zool J Linn Soc 151:423-437

Christiansen P (2008) Evolution of skull and mandible shape in cats (Carnivora: Felidae). PLoS ONE 3:e2807

Christiansen P, Mazák JH (2008) A primitive Late Pliocene cheetah, and the evolution of the cheetah lineage. PNAS 106:512-515

Clarke KR (1993) Non-parametric multivariate analyses of changes in community structure. Austral Ecol 18:117-143

Dayan T, Simberloff D (2005) Ecological and community-wide character displacement: the next generation. Ecol Letters 8:875-894

Dayan T, Simberloff D, Tchernov E et al (1990) Feline canines: community-wide character displacement among the small cats of Israel. Am Nat 136:39-60

Driscoll CA, Menotti-Raymond M, Roca AL et al (2007) The Near Eastern origin of cat domestication. Science 317:519

Fauth JE, Bernardo J, Camara M et al (1996) Simplifying the jargon of community ecology: a conceptual approach. Am Nat 147:282-286

Freudenberg W (1910) Die Saügetierfauna des Pliocäns und Postpliocäns von Mexiko. 1. Carnivoren Geol Paläont Abh 8:193-231

Geigl EM, Grange T (2018) Of cats and men: ancient DNA reveals how the cat conquered the ancient world. In: Lindqvist C, Rajora O (eds) Paleogenomics. Population genomics. Springer, Cham, pp 307-324

Geraads D (1980) Un nouveau felide (Fissipeda, Mammalia) du Pleistocene moyen du Maroc: Lynx thomasi n. sp. Géobios 13:441-444

Giannini NP (2003) Canonical phylogenetic ordination. Syst Biol 52:684-695

Gonyea WJ (1976) Adaptive differences in the body proportions of large felids. Acta Anat 96:81-96

Grafen A (1989) The phylogenetic regression. Phil Trans Royal Soc B 326:119-157

Haas SK, Hayssen V, Krausman PR (2005) Panthera leo. Mammalian Species 762:1-11

Hammer $\varnothing$, Harper DAT, Ryan PD (2001) PAST: paleontological statistics software package for education and data analysis. Palaeontol Electron 4:1-9

Hemmer H, Kahlke RD, Vekua AK (2010) Panthera onca georgica ssp. nov. from the early pleistocene of dmanisi (Republic of Georgia) and the phylogeography of jaguars (Mammalia, Carnivora, Felidae). N Jb Geol Paläont Abh 257:115-127

Johnson WE, Dratch PA, Martenson JS et al (2006) The late Miocene radiation of modern Felidae: a genetic assessment. Science 311:73-77

Kiltie RA (1984) Size ratios among sympatric neotropical cats. Oecologia 61:411-416

Kitchener AC, Breitenmoser-Würsten C, Eizirik E et al (2017) A revised taxonomy of the Felidae: the final report of the Cat Classification Task Force of the IUCN Cat Specialist Group. Cat News Special Issue 11:80

Koch PK, Barnosky AD (2006) Late quaternary extinctions: state of the debate. Annual Rev Ecol Evol Syst $37: 215-250$

Kreft H, Jetz W (2010) A framework for delineating biogeographical regions based on species distributions. J Biogeogr 37:2029-2053

Kurtén B (1965) The pleistocene felidae of Florida. Bull Florida State Mus 9:215-273

Kurtén B (1968) Pleistocene mammals of Europe. Aldine Publishing Company, Chicago, IL, pp 88-90

Kurtén B (1985) The pleistocene lion of Beringia. Ann Zool Fenn 22:117-121

Kurtén B, Anderson E (1980) Pliocene cats of North America. Columbia University Press, Nueva York

Lemon RR, Churcher CS (1961) Pleistocene geology and paleontology of the Talara region, northwest Peru. Am J Sci 259:410-429

Lewis ME, Lague MR (2010) Interpreting sabertooth cat (Carnivora; Felidae; Machairodontinae $\dagger$ ) postcranial morphology in light of scaling patterns in felids. In: Goswami A, Friscia A (eds) Carnivoran evolution: new views on phylogeny, form and function. Cambridge University Press, Nueva York, pp $411-465$

Madurell-Malapeira J, Alba DM, Moyà-Solà S et al (2010) The Iberian record of the puma-like cat Puma pardoides (Owen, 1846) (Carnivora, Felidae). CR Palevol 9:55-62

Meachen-Samuels J, Van Valkenburgh B (2009a) Craniodental indicators of prey size preference in the Felidae. Biol J Linn Soc 96:784-799

Meachen-Samuels J, Van Valkenburgh B (2009b) Forelimb indicators of prey-size preference in the Felidae. J Morphol 270:729-744 
Montellano-Ballesteros M, Carbot-Chanona G (2009) Panthera leo atrox (Mammalia: Carnivora: Felidae) in Chiapas, Mexico. Southwest Nat 54:217-222

Morales M (2012) Morfología funcional en los ensambles de félidos: efectos biogeográficos continentales, filogenéticos, y de las extinciones pleistocenas. Dissertation, Universidad Nacional de Tucumán

Morales M, Giannini NP (2010) Morphofunctional patterns in Neotropical felids: species coexistence and historical assembly. Biol J Linn Soc 100:711-724

Morales M, Giannini NP (2013a) Pleistocene extinctions and the perceived morphofunctional structure of the Neotropical felid ensemble. J Mammal Evol 21:395-405

Morales M, Giannini NP (2013b) Ecomorphology of the African felid ensemble: the role of the skull and postcranium in determining species segregation and assembling history. J Evol Biol 26:980-992

Morgan GS, Seymour KL (1997) Fossil history of puma and cheetah-like cat in Florida. Bull Florida Mus Nat His 40:177-219

Price MF, Byers AC, Friend DA et al (eds) (2013) Mountain geography: physical and human dimensions. University of California Press, California

R Core Team (2020) R: a language and environment for statistical computing. R Foundation for Statistical Computing, Vienna, Austria. Available from https://www.R-project.org/. Accessed November 2020

Ray CE (1964) The Jaguarundi in the Quaternary of Florida. J Mammal 45(330):332

Ricklefs RE (1998) Invitación a la Ecología, la economía de la Naturaleza, 4th edn. Editorial Médica Panamericana, Buenos Aires

Seymour K (2015) Perusing Talara: overview of the late pleistocene fossils from the tar seeps of Peru. Nat His Mus LA County Sci Ser 42:97-109

Sicuro FL, Oliveira LFB (2010) Skull morphology and functionality of extant Felidae (Mammalia: Carnivora): a phylogenetic and evolutionary perspective. Zool J Linn Soc 161:414-462

Simpson GG (1941) Large Pleistocene felines of North America. Am Mus Nov 1136:1-27

Stayton CT (2015) The definition, recognition, and interpretation of convergent evolution, and two new measures for quantifying and assessing the significance of convergence. Evolution 69:2140-2153

Stayton CT (2018) convevol: analysis of convergent evolution. R package version 1.3. Available from https ://CRAN.R-project.org/package=convevol

Stokstad E (2009) On the origin of ecological structure. Science 326:33-35

Sunquist ME, Sunquist FC (2002) Wild Cats of the World. University of Chicago Press, Chicago

Sunquist ME, Sunquist FC (2009) Family felidae. In: Wilson DE, Mittermeir RA (eds) Handbook of mammals of the world, vol 1. Carnivores. Lynx editions, Barcelona, pp 54-168

Tellaeche CG, Reppucci JI, Morales M et al (2018) External and skull morphology of the Andean cat and Pampas cat: new data from the high Andes of Argentina. J Mammal 99:906-914

ter Braak CJF (1995) Ordination. In: Jongman RHG, ter Braak CJF, van Tongeren OFR (eds) Data analysis in community and landscape ecology. Cambridge University Press, Cambridge, pp 91-173

Turner A, Antón M (1997) The big cats and their fossil relatives. Columbia University Press, New York

UNEP World Conservation Monitoring Centre (2002) Mountain watch: environmental change and sustainable development in mountains. UNEP World Conservation Monitoring Centre, Cambridge, UK

Werdelin L (1985) Small pleistocene felines of North America. J Verteb Paleontol 5:194-210

Werdelin L, Yamaguchi N, Johnson WE et al (2010) Phylogeny and evolution of cats (Felidae). In: Macdonald DW, Loveridge AJ (eds) Biology and conservation of wild felids. Oxford University Press, Oxford, pp 59-88

Yamaguchi N, Cooper A, Werdelin L et al (2004) Evolution of the mane and group-living in the lion (Panthera leo): a review. J Zool 263:329-342

Zhanxiang Q (2003) Dispersals of Neogene Carnivorans between Asia and North America. Bull Am Mus Nat Hist 279:18-31

Publisher's Note Springer Nature remains neutral with regard to jurisdictional claims in published maps and institutional affiliations. 